\title{
UNDERSTANDING IMPACTS OF TIME AND COST RELATED CONSTRUCTION RISKS ON OPERATIONAL PERFORMANCE OF PPP PROJECTS
}

\author{
Hemanta DOLOI \\ Faculty of Architecture, Building and Planning, The University of Melbourne, Victoria 3010, \\ Australia \\ E-mail:hdoloi@unimelb.edu.au
}

Received 17 November 2011; accepted 21 February 2012

\begin{abstract}
The risk attributes in construction project is one of the widely published topics, yet there is no or little investigation whether or not risks associated with construction phase propagate over operational phase. As operation phase of the PPP projects is significantly long compared to the construction phase, understanding the impact of time and cost related construction risks over operation phase is quite important. In this research, risk attributes associated with the PPP procurement method have been identified across three dimensions, time, cost and operational performance. A questionnaire survey was used for collecting data in seven major PPP projects in Australia. Based on standard statistical methods and factor analysis, a number of key risk factors influencing time, cost and operational performance have been extracted. The research revealed that site conditions and design complexity is one of the most critical risk attribute influencing time performance in projects. Similarly, market dynamics is the most critical attribute influencing both construction cost and operational performance in PPP projects. Based on regression modeling, partner's dispute was found to be a good determinant of time and cost performance. Technical obsolescence has significant impacts on the operational performance of PPP projects. It was revealed that the design complexity, financial structure and government policy are the three main common factors affecting risks across time, cost and operational performance in PPP projects. It is anticipated that the findings will impact the construction firms for improving the front-end risk management capability for efficient positioning within the competitive business environment.
\end{abstract}

KEYWORDS: Construction risks; Operational risks; Public-private-partnerships; Factor analysis; Multiple regression

\section{INTRODUCTION}

Risk management is a topic area that interests most industry sectors and particularly in the construction industry. However, traditional risk management framework applied in construction industry predominately focuses on management of risks over construction phase. In fact, the current risk management processes are significantly inadequate in managing risks associated with issues such as selection of procurement routes, contractual arrangements, management of stakeholders, organisational complexity and operational performance and de-investment decisions (PMBOK, 2008). A contemporary risk management framework must be able to deal with every increasing complexity with bigger stakes and 
stronger constraints in modern projects (Marle et al., 2010; Majamaa et al., 2008). In the capital intensive construction industry, the consequences of unidentified or unmanaged risks in project execution can have significantly adverse impact on the operational performance. While a stringent risk management practice over project execution potentially result in effective project delivery, risks associated with the selection of project procurement greatly influence the final project outcomes (Baker et al., 1999). Thus, risks associated with the selection of an appropriate procurement route should be effectively managed for achieving long run success in projects.

The procurement of major infrastructure projects is typically complex, highly competitive, costly and time consuming which impels public sector clients to encourage private sector investment to spread the financial burden and to exploit the expertise. Public-private-partnerships (PPP) form a contractual relationship between the public sector and the private sector where the private sector takes all or part of the responsibility of the Government's functions (Groak, 1994; Kuronen et al., 2011). PPP is thus seen as a vehicle to transfer most risks to the private parties and yet derive maximum value for money in the public sector projects. It has been increasingly evident that driver for selecting PPP projects is fundamentally shifting from the market or demand driven attributes to the project based attributes (Doloi, 2010). As a result, the performance of project based attributes such as time and cost management gets priority during the construction phase. The operational performance in the post construction phase such as usability or utilization of the project facility often gets hidden in the project evaluation context (Cheung et al., 2010; Yuan et al., 2010). While PPP is becoming one of the major procurement methods in most public sector projects in Australia, scrutiny of the operation performance becomes an important issue among the parties. There is an increasing consensus for understanding and evaluation of risks in relation to the success of PPP across the entire project life cycle.

This paper aims to identify the critical risks pertinent in both the construction and operation phases of PPP project and set a benchmark on the impacts and consequences in three dimensions namely cost, time and operational performance of the project. In order to meeting the objectives, firstly, the risk attributes associated with cost, time and operation performance in PPP projects have been identified from the existing literature. Secondly, adopting a questionnaire survey approach, data have been sourced from industry to reflect the impacts of the risk attributes on cost, time and operational performance. Thirdly, statistical analysis namely factor analysis is performed to reduce the attributes into smaller meaningful groups across all three categories for understanding the similarities and differences of the risk attributes over project life cycle. Fourthly, the multivariate regression analysis was then performed for developing some sort of predictive models on cost, time and operational performance of PPP projects. The remainder of the paper will focus on the detailed processes of conducting the research, discussion of findings including highlights of the contributions made in relation to the existing body of knowledge in the field.

\section{PUBLIC-PRIVATE PARTNERSHIPS AND INFRASTRUCTURE PROCUREMENT}

The procurement method selected for any project sets the benchmark for identifying the responsibilities of stakeholders involved and defines the financial and legal boundaries of the project (Lam, 2004). Therefore, project procurement strategy is seen as a key consideration in the execution of any business venture or construction development and greatly influences the final project outcomes. For this rea- 
son, project procurement strategy is strongly associated with risk management.

In the construction industry, the procurement route chosen significantly impact on the successful project outcomes. PPP forms a contractual relationship between the public sector and the private sector where private sector takes all or part of the responsibility of the Government's functions. PPP has been a common form of procurement for many public sector infrastructure projects in the United Kingdom and which is then followed by many other countries around the globe. In the UK, the term Private Finance Initiative (PFI) is commonly used (Smith and Merna, 2006; Cheung et al., 2010). Among many other countries, PPP has been adopted as one of the prime procurement methods for renewing or developing public infrastructure in Australia over the last few decades (Wooward, 1997; Doloi, 2008). However, at present a well-developed PPP market does not exist in Australia due to lack of coherence policies across the states and the Commonwealth governments. The multiple Governments, each with their own policies on privatisation and PPP, prevent them from developing a strategy that delivers interstate homogeneity (Doloi and Raisbeck, 2007). However, despite various technology and terminology differences, there is a tendency towards homogeneity: e.g. the Victorian Department of Treasury and Finance is in the course of preparing the whole of Government standardised commercial principles and contractual provisions. Australian tax legislation and in particular Section 51AD and Division 16D of the Commonwealth Income Tax Assessment Act 1936 make tax deduction for certain costs associated with ownership, including interest charges, depreciation and maintenance costs impossible to be applied to private sector consortia (SDTF, 2006).

Particularly in Victoria, the Partnerships Victoria policy was introduced in 2000 providing the framework for a whole government approach to providing public infrastructure and related ancillary services through publicprivate-partnerships. Although each project has its own unique complexity, the Partnerships Victoria policy brings consistency to the procedures for managing and implementing projects. The policy focuses on gaining value for money including whole-of-life costing, managing risks and protecting the public interest. The State retains delivery control of core public services. Once government has determined that new public infrastructure and related ancillary services are required, departments and agencies need to consider carefully how they can best be delivered. The method of delivery varies from traditional ("design and construct") for simple projects to public-private partnerships for complex projects (Jin and Doloi, 2009; Xu et al., 2011).

Based on a number of completed projects in Australia, PPP is perceived to be quite effective in terms of meeting the key performance indicators in project delivery context. However, considering the operational perspective, all these projects are not free from criticism in terms of meeting the operational objectives and delivering true value for money. While effective project delivery strongly links with efficient risk management program over construction phase, there is no clear evidence on how the construction related risks potentially affect the operational performance over post construction phase. Focusing on the PPP procurement method, this research predominantly discusses the underlying risks related to cost and time performance over construction phase and operational performance over post construction phase.

\section{PREVIOUS WORKS IN CONSTRUCTION RISK FACTORS}

In the PPP projects, the public sector seeks to overcome the limited ability of the Government to finance social and infrastructure 
projects, to transfer part of the risk to the private sector whilst utilizing the management skills and experience of the private sector to raise the quality of the services provided and increase the efficiency of public infrastructure management (Poulter, 2004). However the process of PPP is not that simple as it sounds. Due to the involvement of a multitude of stakeholders, the risks associated in the PPP process are multifaceted. Managing the risks in $\mathrm{PPP}$ projects not only demands effective execution of core processes in the project management plan but also exerts a significant demand on a clear understanding of the PPP process and identification of all the risks associated with the wider stakeholders over the PPP lifecycle.

While cost and time performances are fundamentally important in measuring success in project delivery, understanding of the operational performance in post construction phase is a critical issue for achieving overall success in projects. Based on the published research, it has been evident that numerous works have been done to identify the risk factors in terms of cost and time performance of projects (Lyons and Skitmore, 2004; Kaming et al., 1997; Frimpong et al., 2003). Yet, how such cost and time performance links to the operational success in the project is still a topic for investigation. Based on a comprehensive literature search on the investigation of risks in construction projects, a few selected research are summarised below.

Baloi and Price (2003) discussed the core risk factors in construction project using fuzzy set theory. They classified the risk factors of cost overrun into seven categories, namely estimator related, design related, competition related, fraudulent practices related, construction related, economic related and political related risks. Investigating the financial viability analysis and capital structure, Zhang (2005b) concluded that there are predominately two forms of risks namely, construction risk and economic risks, associated with the privately funded infrastructure projects. While the construction risks are characterised by cost overrun and schedule delays, the economic risks usually arise as a result of long concession period. The economic risks include demand risks, variation of operation and maintenance costs, fluctuations in exchange and interest rates and inflations. However, exclusion of any analysis on the crossover of both risks and their management over the currency of the project made their findings incomprehensive in the context of contemporary research (Zhang, 2005b).

Based on the analysis of a green field BOT project in Greece, Xenidis and Angelides (2005) identified 27 key financial risks and classified them considering both the project's lifecycle phase and the source for each risk. The findings revealed three major categories of risks namely state-rooted, concessionaire-rooted and market-rooted associated with BOT projects. However, their research did not include the discussion on how any risks from one category potentially propagate through to other category and impact over the project life cycle (Xenidis and Angelides, 2005). Focusing on a number of international construction projects, Dikmen et al. (2007) divided project risks into two classes: country risks and project specific risks. Country risks describe the political and macroeconomic risk factors in the projects, such as international relations, cultural/religious difference, macroeconomic conditions, attitude towards foreign investments and legal system maturity. Project specific risks include technical risks, managerial risks, resource risks, productivity risks, design risks, payment risks, client risks and subcontractor risks. In the United States, Nassar et al. (2005) conducted a study of the construction risk factors for the cost overrun. Based on the paving projects in the US, they identified the causes of cost overruns including unpredicted additions, balanced final field measurement, hazardous/ controlled waste investigation and cleanup. 
Investigating the risk management practices in Chinese construction industry, Tang et al. (2007) revealed that most project risks are common concern to the project participants. While the current industry practice shows a shift from risk transfer to risk reduction, the risk management systems are mostly inadequate in managing project risks. Most notably, a lack of joint risk management mechanism among the partners has been reported as one of the key barriers to adequate risk management (Tang et al., 2007). In Australia, Doloi (2010) investigated the causes of cost overruns in different project phases from the perspective of each stakeholder using soft systems methodology, and summarised potential risk factors from political, economic, financial, technical and attitudinal perspectives. However, how these factors potentially impact on the operational phase of the project was not part of this investigation. In Indonesia, Kaming et al. (1997) explored the time and cost overruns in major construction projects in two cities: Jakata and Yogyakarta. The factors for cost overruns were identified as inflationary increase in material cost, inaccurate cost estimating, and project complexity. Potential risks for time performance include design changes, low labour productivity and inadequate planning. In Malaysia, Sambasivan and Soon (2007) examined the risk factors of project delays in the construction industry. They identified ten most important causes for delays from 150 survey responses which include improper planning and design, poor site management, incompetence of contractor/subcontractors, labor/material/equipment shortage, communication and stakeholder management.

According to the operational performance of construction project, Partnerships UK investigated over 450 PFI projects in the UK, including transport system, hospital projects, school projects, accommodation and training facilities, etc. (Partnerships UK, 2006). They identified critical factors for the performance in operational phase, include payment mechanism in the contract, flexibility of the contract, benchmarking and reviewing system, as well as communication and relationship between project participants. However, the quantitative impact of these factors and their relative impacts on the operational performance in projects were not reported in the investigation.

In Thailand, Ghosh and Jintanapakanout (2004) summarised the key risk factors within infrastructure projects, and studied the importance of the risk factors using a survey on a mass rapid-transit underground rail project. They concluded that financial/economic risk has the most influential impact on the infrastructure project, followed by contractual/legal risk, subcontractors-related risk and operational risk.

In China, Zou et al. (2007) studied the risks associated with time, cost and quality performance and asserted that the variation by clients, inflation of construction materials and design variation are the most significant risk factors for cost performance in the project. Similarly, project funding problem, variation by client and inadequate program scheduling are found to be the most important factors related to time performance. In terms of project quality, tight project schedule, poor management ability and unavailability of human resources are the major risks. Extending their study into risks associated with environmental and safety issues, it was revealed that site management, tight project schedule and project funding problems are the top causes of environmental and safety risks.

Having reviewed the literature, it has been evident that the construction risks in project development and execution contexts have been widely studied. However, how construction risks associated with time and cost performance links to the operational performance over post construction phase have not been the focus in the past studies. As the operational performance of PPP projects plays a significant 
role in achieving long term success, comparison or contrast of risks associated with cost, time and operational performance in PPP projects is an important topic for investigation. The PPP procurement route, where the responsibility and risks are shared between public and private sectors, exhibits a different risk spectrum across the perspectives of concerned partners in the project. Thus, the main objectives of this research are as follows:

- To identify the relative importance of cost, time and operational performance related risks in projects procured through PPP methods;

- To understand the latent properties of these risk attributes in order to benchmark the most critical factors; and

- To investigate the similarities and contrasts of the impacts of risk attributes across cost, time and operation performance in PPP projects.

\section{RESEARCH METHODOLOGY}

The focus of this study is predominately on the cost, time and operational related risks in construction projects procured through the PPP procurement route. In order to understand these risks, a huge amount of documented data on completed PPP projects is required (Frimpong et al., 2003; Field, 2005; Cheung et al., 2010). As mentioned earlier, regardless of the extent of previous study on construction risks in Australia, the study on PPP risks impacting cost, time and operational performance in projects was not found widespread. Due to nonavailability of specific data on locally completed projects for this study, a questionnaire survey approach was deemed appropriate in this research (Iyer and Jha, 2005; Kumaraswamy and Matthews, 2000). Risk attributes affecting cost, time and operational performance were listed out through literature survey and interviews with selected professionals from local construction industry. A separate section was included to capture the performance measures in terms of cost, time and operational success in the selected projects. Appendix A shows the selection risk attributes used to capture the respondent's perceived knowledge across risks associated with cost, time and operational performance in PPP projects.

In this study, 169 questionnaires were distributed among individual employees comprising owner/facility manager, head contractor/project manager, contract administration, quantity surveyor/cost controller, project engineer, designer and site supervisor and foremen. These professionals were selected from a total of seven current and past PPP projects in Victoria. The respondents were asked to select one of their past or current PPP projects and reflect on risk issues and perceived impacts associated with cost, time and operational performance. A 5-point likert scale was used to capture the preferences of respondents in the questionnaire. While cost and time related risks are easily understood among the respondents through their active participations in the construction stage, the judgment on operational performance was reportedly based on operational statistics, media reports, visual evidence and personal experiences. The respondents were asked separately to indicate an appropriate level (1-5 point likert scale) in terms of cost, time and operational success in same projects. While time and cost performances were measured in terms of on-time and within budget delivery respectively, operational performance was measured in terms of ontime commissioning, meeting the operational expectations and Key Performance Indicators (KPIs) stated in the product disclosures statements. Table 1 shows the respondents profile, their experiences and proportion of completed projects delivered through PPPs. Of the 169 questionnaires sent out across seven selected PPP projects, 114 responses were received which was approximately a $67.5 \%$ response rate. This is quite a reasonable response rate and thus data analysis is deemed appropriate (Nunnally, 1978; Vaus, 2001). 
Table 1. Summary of respondents' profile

\begin{tabular}{lllll}
\hline Field of work & & & Experience (years) \\
\cline { 1 - 1 } Roles & \%of sample & & No. of years & \% of sample \\
\hline Architect/designer/project engineer & $10.7 \%$ & & $<5$ & $11 \%$ \\
Contract administrator & $16.0 \%$ & $6-10$ & $27 \%$ \\
Head contractor/project manager & $34.0 \%$ & $11-15$ & $25 \%$ \\
Quantity surveyor & $24.0 \%$ & $16-20$ & $7.0 \%$ \\
Project owner/facility manager & $15.3 \%$ & $>20$ & $30 \%$ \\
\hline
\end{tabular}

\section{IDENTIFICATION OF THE RISK ATTRIBUTES}

Preparation of a list of comprehensive risk attributes associated with PPP projects was a critical first step to success of this study. In this research, the risk attributes refer to the events representing project development practices from planning, design, commissioning, operation to political, contractual and financial dimensions in the PPP procurement route. By conducting a systematic background review, the significant risk attributes associated with PPP construction processes have been identified from the published literature (Lam, 2004; Daube et al., 2008; Smith and Merna, 2006; Partnerships UK, 2006; Akintoye and MacLeod, 1997; Baker et al., 1999; Baloi and Price, 2003; Bing et al., 2005; Ghosh and Jintanapakanont, 2004; Iyer and Jha, 2005; Tang et al., 2007; Zhang, 2005b). For an in-depth understanding and thorough analysis of risk management practices, the list of attributes were further refined based on a pilot study conducted with a client, a senior project manager and a head contractor of a medium sized PPP project in Australia. A set of questions covering a total of 42 key risk attributes across three broad categories namely time, cost and operational performance were then designed to clearly identify the risk related issues and to analyse the impacts in PPP projects. Though the list of this 42 attributes may not be considered exhaustive due to the vast magnitude and fragmented nature of construction industry and construction environment, the list cov- ered risk attributes pertaining to cost, time and performance characteristics in variety of PPP projects (Zou et al., 2007; Akintoye and MacLeod, 1997; Lyons and Skitmore, 2004). To guide the respondents for better understanding of the questions and appropriate structuring of their responses across the issues, these 42 key attributes were categorised into twelve broad headings namely respondent details, planning and design risks, construction risks, operating risks, commissioning risks, post-construction market risk, stakeholder's issues, political legislative and regulatory risks, financial risks, asset ownerships, environment risks and force majeure. The categorisation of the attributes and the brief description of the questions are presented in Appendix A. The base data was gathered to facilitate the quantitative analysis on the responses to work out a meaningful relationship among the attributes.

In order to understand the impacts and contributions of these risk attributes in project, the statistical approach was considered appropriate. Two methods namely multivariate regression and factor analysis were employed by using Statistical Package for Social Sciences (SPSS) software package (Field, 2005). A typical first step in statistical analysis of data is to determine the rank of all the attributes in the order of their relative impacts on projects. In determining the relative importance of the numerous quantitative variables, a multivariate correlation analysis may be performed on the collected data. However, multivariate correlation analysis was not quite useful due to considerable multicollinearity in the data (Iyer and 
Jha, 2005). This is due to the fact that many of the identified attributes and related questions were closely related. Thus, the factor analysis technique has been adopted to overcome the multicollinearity problem in this research (Trost and Oberlender, 2003; Iyer and Jha, 2005).

Before proceeding to the analysis of the collected data, in order to establish the strength of the measurement model, reliability and validity tests were performed on the raw data (Hair et. al. 1998). Three tests are used to assess reliability and validity: Cronbach's alpha (Ca), Composite Factor Reliability (CFR) and Average Variance Extracted (AVE). For Cronbach's alpha, a cut-off value of 0.7 is used to indicate the acceptable level of internal consistency (Nunnally, 1978). Composite Factor Reliability score is superior to Cronbach's Alpha measure of internal consistency since it uses item loadings obtained within the theoretical model (Fornell and Larcker, 1981). Cronbach's Alpha weighs all items equally without considering their factor loadings. However, the interpretation of both the tests in relation of internal consistency measure is the same. Nunnally (1978) also recommended the threshold value of 0.7 as an indicator of adequate CFR. The Average Variance Extracted (AVE) was used to assess the convergent validity of the latent variables (Fornell and Larcker, 1981). AVE measures the amount of variance that a latent variable captures from its measurement attributes relative to the amount of variance due to measurement errors. As for AVE, Fornell and Larcker (1981) suggested a score of 0.5 as an acceptable level. Given $\lambda \mathrm{i}$ is the $\mathrm{i}^{\text {th }}$ factor loading of indicator on a factor, CFR and AVE are determined using the following expressions:

Composite Factor Reliability (CFR) =

$$
\frac{\left(\sum_{i} \lambda_{i}\right)^{2}}{\left(\sum_{i} \lambda_{i}\right)^{2}+\sum_{i}\left(1-\lambda_{i}^{2}\right)}
$$

and

Average Variance Extracted $(\mathrm{AVE})=$

$$
\frac{\sum_{i} \lambda_{i}^{2}}{\sum_{i} \lambda_{i}^{2}+\sum_{i}\left(1-\lambda_{i}^{2}\right)}
$$

Using the respondent's responses on the measure attributes, the scores of reliability measures for all three categories are tested using the above formulae. Cronbach's alpha (Ca) of 0.886 indicates a good overall reliability of the questionnaire sample. The values of CFR and AVE being 0.887 and 0.896 respectively show a similar strength of the sample in the analysis.

\section{FACTOR ANALYSIS}

Factor analysis is a powerful method of statistical analysis which aims at providing greater insight of relationship among numerous correlated, but seemingly unrelated, variables in terms of a relatively few underlying variants. Factor analysis is primarily used for data reduction and summarisation (Iyer and Jha, 2005). If there is large number of variables in the dataset and most of them are correlated, they must be reduced to a manageable level for appropriate interpretation (Chan and Kumaraswamy, 1997). Relationships among sets of many interrelated variables are examined and represented in terms of a few underlying factors.

The factor analysis comprises a two-step process. Initially, the elements are resolved into their principal components analysis. Determining the principal components requires transforming the data into orthogonal variables using the eigenvectors of the matrices of the original variables. Each principal component is a linear transformation of original variables. Because the linear components are orthogonal, no independence or multicollinearity exists in the transformed data (Field, 2005; Trost and Oberlender, 2003). 
Once the principal components are determined, a factor rotation is performed. Factor rotation involves rotating the principal components about the axis of original variables. The factor rotation preserves the orthogonality of the principal components, but a new transformation matrix is formed with each rotation. Different methods exist for performing factor rotations (Field, 2005; Child, 1990). A preferred method, known as the method of maximum variance, results in a series of rotations wherein each rotation creates a new variable or factor such that the maximum remaining variance in the data is explained by that variable (Trost and Oberlender, 2003).

\section{RESULTS AND FINDINGS}

The following sections will discuss some key findings resulting from factor analysis.

\subsection{Component extracted}

In this study, the principal components analysis is adopted to reduce the highly correlated project attributes into a smaller number of key factors. The factor analysis was performed on the attributes across all three categories of responses namely, cost, time and operational performance. A total six principal components (factors) were extracted for cost performance measure as shown in Table 2 . Similarly, a total of seven each for time and operational performance categories are shown in Tables 3 and 4 respectively. These principal components are extracted by specifying the minimum initial eigenvalue of 1.0. Scree plots to graph the eigenvalues against the number of total components were generated in the data reduction process (Field, 2005). It was found that the graph is almost flat from the sixth component for all cost and seventh components for time and operational categories, indicating that each successive component accounts for decreasing amounts of the total variance.
The respective components for cost, time and performance cumulatively explained $82.85 \%$, $84.43 \%$ and $84.70 \%$ of the total variances as shown in the third columns in Tables 2, 3 and 4 respectively. A few of the critical factors across all three categories are discussed below.

\subsection{Factors associated with cost management}

The factor loadings shown in column 2 of Table 2 indicate which attribute belong to which factor. The first factor that has the largest total variance of $22.65 \%$ can explain the most important attributes in cost performance measure. Amongst five attributes grouped under Factor 1 (renamed as Planning and Design), the first attribute (with factor loading = 0.866) that change in project scope underpins the cost performance over project development and implementation phases. The second attribute, defects in design with the factor loading $=0.835$ is found to have significant impact on cost performance in PPP projects. Changes in Output Specification (third attribute with factor loading $=0.569$ ) plays a significant role in planning and design due to perhaps conflicting expectations among the stakeholders. While the public partner likes to push for a high-end specification for achieving an optimal value-for-money outcome, the private parties tend to stick to the contract specifications as close as possible. The similar principle prevails in the justification of the innovative design attribute with a factor loading of 0.543. Delay in operation, which is usually the result of the delay in construction and commissioning, is found to have impact on cost performance with a factor loading of 0.538 .

The second factor (renamed as Communication), which is independent of the first factor and contains six key project attributes with the second largest variation of $18.05 \%$ explaining the criticality of the stakeholder management and communication protocols in 
the PPP project. Lack of cooperation from the government with factor loading of 0.853 is one of the most significant attributes in this factor. Misinterpretation of contract (with factor loading of 0.850) in construction phase exerts cost performance in overall projects. Failure/ delay in obtaining permit/approval due to bureaucracy in government organizations (with factor loading of 0.716 ) is found to be crucial in PPP project. Partner's dispute was found to have significant impact (with a factor loading of 0.577). Failure or delay in material delivery scored 0.507 for the project. Due to involvement of a multitude of stakeholders in the PPP process, a measure of real time communication (factor loading of 0.476) between stakeholders should impact positively on overall cost outcomes in projects.

Table 2. Rotated factor loadings of eight key risk factors influencing project cost performance

\begin{tabular}{|c|c|c|}
\hline Variables & Factor loading & $\begin{array}{l}\text { Variance } \\
\text { explained }\end{array}$ \\
\hline \multicolumn{3}{|l|}{ Factor 1: Planning and design } \\
\hline 5. Change in scope & 0.866 & \multirow{5}{*}{$22.65 \%$} \\
\hline 4. Defects in design & 0.835 & \\
\hline 1. Changes in output specification & 0.569 & \\
\hline 2. Innovative design & 0.543 & \\
\hline 11. Delay in operation & 0.538 & \\
\hline \multicolumn{3}{|l|}{ Factor 2: Communications } \\
\hline 23. Lack of cooperation of the government & 0.853 & \multirow{6}{*}{$18.05 \%$} \\
\hline 30. Misinterpretation of contract & 0.850 & \\
\hline 32. Failure/delay in obtaining permit/approval & 0.716 & \\
\hline 29. Partner's disputes & 0.577 & \\
\hline 9. Failure/delay in material delivery & 0.507 & \\
\hline 26. Lack of communication between stakeholders & 0.476 & \\
\hline \multicolumn{3}{|l|}{ Factor 3: Site conditions } \\
\hline 38. Commercial rights due to development in vicinity & 0.871 & \multirow{4}{*}{$14.05 \%$} \\
\hline 41. Site contamination & 0.858 & \\
\hline 37. Adverse changes in tax & 0.614 & \\
\hline 42. Force Majeure & 0.520 & \\
\hline \multicolumn{3}{|l|}{ Factor 4: Market dynamics } \\
\hline 36. Adverse changes in interest rates & 0.883 & \multirow{4}{*}{$11.60 \%$} \\
\hline 35. Financial failure of private consortium & 0.856 & \\
\hline 21. Unanticipated inflation & 0.716 & \\
\hline 33. Unavailability of financing & 0.674 & \\
\hline \multicolumn{3}{|l|}{ Factor 5: Construction risk } \\
\hline 6. Constructability & 0.870 & \multirow{4}{*}{$8.85 \%$} \\
\hline 28. Destructive industrial action & 0.840 & \\
\hline 8. Unforeseen site condition & 0.774 & \\
\hline 7. Failure/delay in site acquisition & 0.753 & \\
\hline \multicolumn{3}{|l|}{ Factor 6: Policy, legislation \& regulation } \\
\hline 17. Unanticipated economic downturn & 0.119 & \multirow{4}{*}{$7.65 \%$} \\
\hline 18. Increased competition & 0.112 & \\
\hline 24. Misunderstanding the role of stakeholders & 0.743 & \\
\hline \multirow[t]{2}{*}{ 31. Adverse changes in law, policy or regulations } & 0.722 & \\
\hline & \multicolumn{2}{|c|}{ Total variance explained $=82.85 \%$} \\
\hline
\end{tabular}


The third factor (named as Site Conditions) explains the impacts of site related factors on project cost performance with a total variance of $14.05 \%$. This factor also explains a similar variance (the third factor with total variance explained as $14.35 \%$ as shown in Table 4) for overall performance of project. The first attribute influencing cost performance as shown in Table 2 is the effect on commercial rights due to the vicinity development with a factor loading of 0.871 . Site contamination (with a factor loading of 0.858 ) is also found to have significant impact on cost performance of projects. Adverse changes in tax are found to have impact with a factor loading of 0.614 . Force majeure is found to have impacted cost performance by a factor loading of 0.520 .

The forth factor, named as Market Dynamics, explains the impacts of market fluctuations in PPP project development environment with a total variance of $11.60 \%$. Due to involvement of many stakeholders, the financial structure for PPP project is usually complex. Thus change of market condition over currency of project expects to impact the overall cost performance of the project substantially. A number of projects currently show such evidence of significant cost overruns across Australia. For the sake of brevity, the remaining two factors have not been discussed in this manuscript.

\subsection{Factors associated with time management}

The factor loadings shown in column 2 of Table 3 indicate which attribute belong to which factor in time management context. The first factor that has the largest total variance of $21.65 \%$ can explain most important attributes in time management. Amongst six attributes grouped under Factor 1 (renamed as Market fluctuations), the first attribute, increased competition with the factor loading = 0.913 has a significant impact on time performance in projects. Existing commercial rights or associated disputes (second attribute with factor loading $=0.887$ ) plays a significant role in time management in PPP projects. Change of interest rates (factor loading of 0.877 ) over the currency of project due to possible involvement of global investors is found to be a critical attribute in time performance. The attribute, speculation on economic recessions (factor loading of 0.863) potentially influences time drag in projects. Adverse changes in tax systems and speculative inflation impact on time performance with factor loadings in the order of 0.843 and 0.833 respectively.

The second factor (named as Stakeholder Management) comprising five attributes with $17.55 \%$ total variance explains the importance of stakeholders management over time performance in PPP projects. The first attribute (with factor loading of 0.824) shows a significant impact of stakeholder's role in the successful management of time in projects. Impacts on stakeholders due to adverse change of laws, policies and regulation has significant impact on time performance as well. Similarly, disputes between stakeholders (with factor loading of 0.628) hinder the time management in projects. Due to the involvement of multiple stakeholders in PPP projects, public resistance and activism have significant risk for (factor loading of 0.569) time overrun in projects. Change of stakeholder (factor loading of 0.536) in the project development process obviously tends to add to the overall time in projects. As seen in Table 3, for the sake of brevity, the remaining five factors in time management context have not been discussed in details.

\subsection{Factors associated with the operational performance of PPP projects}

The factor loadings shown in column 2 of Table 4 indicate which attribute belong to which factor in the context of operational performance of projects over post construction phase. The first factor that has the largest total variance of $22.90 \%$ can explain most important attributes in operational performance in projects. 
Amongst six attributes grouped under Factor 1 (renamed as Market Dynamics), the first attributes (with factor loadings of 0.932) that the adverse changes in interest rates during the execution of PPP contracts underpins the total performance over both implementation and operation phases of projects. The second attribute, commercial rights due to vicinity of development with a factor loading $=0.840$ is found to have significant impact on operations of projects. The issue of withdrawal of government supports (with factor loadings of 0.805) in the post construction phase of PPP project can significantly alter the operational performance from the target expected.

Table 3. Rotated factor loadings of key risk factors influencing project time performance

\begin{tabular}{|c|c|c|}
\hline Variables & Factor loading & Variance explained \\
\hline \multicolumn{3}{|l|}{ Factor 1: Market fluctuations } \\
\hline 18. Increased competition & 0.913 & \multirow{6}{*}{$21.65 \%$} \\
\hline 38. Commercial rights due to vicinity of development & 0.887 & \\
\hline 36. Adverse changes in interest rates & 0.877 & \\
\hline 17. Unanticipated economic downturn & 0.863 & \\
\hline 37. Adverse changes in tax & 0.843 & \\
\hline 21. Unanticipated inflation & 0.833 & \\
\hline \multicolumn{3}{|l|}{ Factor 2: Stakeholder management } \\
\hline 24. Misunderstanding the role of stakeholders & 0.824 & \multirow{5}{*}{$17.55 \%$} \\
\hline 31. Adverse changes in law, policy or regulations & 0.812 & \\
\hline 29. Partner' disputes & 0.628 & \\
\hline 27. Public resistance & 0.569 & \\
\hline 25. Change of stakeholder & 0.536 & \\
\hline \multicolumn{3}{|l|}{ Factor 3: Quality control } \\
\hline 32. Failure/delay in obtaining permit/approval & 0.773 & \multirow{5}{*}{$12.35 \%$} \\
\hline 14. Failure/delay in commissioning test & 0.736 & \\
\hline 10. Defects in construction & 0.557 & \\
\hline 41. Site contamination & 0.531 & \\
\hline 28. Destructive industrial action & 0.470 & \\
\hline \multicolumn{3}{|l|}{ Factor 4: Scope variations } \\
\hline 5. Change in Scope & 0.889 & \multirow{4}{*}{$9.55 \%$} \\
\hline 7. Failure/delay in site acquisition & 0.751 & \\
\hline 20. Adverse changes in law, policy or regulations & 0.632 & \\
\hline 42. Force Majeure & 0.453 & \\
\hline \multicolumn{3}{|l|}{ Factor 5: Design complexity } \\
\hline 2. Innovative Design & 0.905 & \multirow{3}{*}{$8.53 \%$} \\
\hline 33. Unavailability of financing & 0.641 & \\
\hline 3. Design Complexity & 0.579 & \\
\hline \multicolumn{3}{|l|}{ Factor 6: Design constructability } \\
\hline 6. Constructability & 0.771 & \multirow{3}{*}{$7.75 \%$} \\
\hline 4. Defects in Design & 0.756 & \\
\hline 8. Unforeseen site condition & 0.455 & \\
\hline \multicolumn{3}{|l|}{ Factor 7: Communication management } \\
\hline 30. Misinterpretation of contract & 0.823 & \multirow{3}{*}{$7.05 \%$} \\
\hline 26. Lack of communication between stakeholders & 0.695 & \\
\hline 23. Lack of cooperation of the Government & 0.573 & \\
\hline
\end{tabular}


Table 4. Rotated factor loadings of eight risk factors influencing operational performance

\begin{tabular}{|c|c|c|}
\hline Variables & Factor loading & Variance explained \\
\hline \multicolumn{3}{|l|}{ Factor 1: Market dynamics } \\
\hline 36. Adverse changes in interest rates & 0.932 & \multirow{6}{*}{$22.90 \%$} \\
\hline 38. Commercial rights due to vicinity of development & 0.840 & \\
\hline 22. Withdrawal of government support & 0.805 & \\
\hline 21. Unanticipated inflation & 0.786 & \\
\hline 33. Unavailability of financing & 0.693 & \\
\hline 7. Failure/delay in site acquisition & 0.612 & \\
\hline \multicolumn{3}{|l|}{ Factor 2: Competitive operations } \\
\hline 15. Demand below anticipation & 0.902 & \multirow{6}{*}{$18.90 \%$} \\
\hline 17. Unanticipated economic downturn & 0.814 & \\
\hline 19. Technical obsolescence & 0.747 & \\
\hline 18. Increased competition & 0.715 & \\
\hline 14. Failure/delay in commissioning test & 0.588 & \\
\hline 30. Misinterpretation of contract & 0.407 & \\
\hline \multicolumn{3}{|l|}{ Factor 3: Site conditions } \\
\hline 41. Site contamination & 0.940 & \multirow{5}{*}{$14.35 \%$} \\
\hline 31. Adverse changes in law, policy or regulations & 0.872 & \\
\hline 39. Service and maintenance & 0.770 & \\
\hline 40. Less residual value & 0.755 & \\
\hline 13. Excessive maintenance and refurbishment & 0.514 & \\
\hline \multicolumn{3}{|l|}{ Factor 8: Stakeholder's management } \\
\hline 27. Public resistance & 0.791 & \multirow{6}{*}{$12.65 \%$} \\
\hline 10. Defects in construction & 0.667 & \\
\hline 28. Destructive industrial action & 0.464 & \\
\hline 26. Lack of communication between stakeholders & 0.653 & \\
\hline 29. Partner' disputes & 0.601 & \\
\hline 31. Adverse changes in law, policy or regulations & 0.529 & \\
\hline \multicolumn{3}{|l|}{ Factor 6: Post construction management } \\
\hline 11. Delay in operation & 0.769 & \multirow{4}{*}{$8.00 \%$} \\
\hline 24. Misunderstanding the role of stakeholders & 0.699 & \\
\hline 12. Adverse impact of core services & 0.689 & \\
\hline 25. Change of stakeholder & 0.615 & \\
\hline \multicolumn{3}{|l|}{ Factor 7: Design complexity } \\
\hline 4. Defects in design & 0.875 & \multirow{4}{*}{$7.90 \%$} \\
\hline 3. Design complexity & 0.834 & \\
\hline 2. Innovative design & 0.665 & \\
\hline 1. Changes in output specification & 0.657 & \\
\hline
\end{tabular}

Unanticipated inflation (with a factor loading of 0.786) is found be to one of the important factors influencing performance of projects. This is due to erosion of the buying power of money and potential change of toll revenue from the contractual viewpoint. Unavailability of financing and delay in site acquisition with factor loading of 0.693 and 0.612 respectively were found to have significant impact on performance as well.

The second factor (renamed as Competitive Operations), which is independent of the first 
factor and contains seven six project attributes with the second largest variation of $18.90 \%$ explained the impacts of the increased competition on the PPP project. Most of the attributes in this factor are similar to the attributes of the first factor under time management category. Amongst six attributes grouped under this factor, the first attribute (with factor loading $=0.902$ ) that the demand of project facility falling below the expected threshold value underpin the operational performance of the project.

The second and third attributes, unanticipated economic recessions and technical obsolescence (with factor loadings of 0.814 and 0.747 respectively) are strongly correlated and pose significant impact on the performance of projects. Increased market competition (with a factor loading of 0.715) plays a significant role in operational performance of PPP projects. Failure in project commissioning test and stakeholders' reluctance for acceptance with a factor loading of 0.588 is found to be a critical attribute. Unclear contract documentations and misunderstanding among the stakeholders is also found to have significant impact on operational performance of projects.

As seen from the above discussions, the overall performance of PPP projects depends on many interrelated factors. Among the six key factors in cost management context, planning and design was found to be most significant followed by clear communications and physical site conditions. All these factors are critical due to the nature of project development structure and the involvement of private participations in public projects in a competitive market environment (Cooper and Chapman, 1987). While government tends to manage all the underlying risks through private agencies in PPP projects, the latter tends to be cynical about clarity, openness and expectations in the project development contexts. Market dynamics is found to be most critical in the contexts of time and operational performance of PPP projects. Change of government legislations and management of stakeholders in the operational project development and operational phases were found to have significant impact on both time and operational performance of projects (Akintoye and MacLeod, 1997). While government encourages private participations in public projects, at the end of the day, the government is accountable to the public on the operational performance of the project. Usability of the services delivered and perceptions of end users play significant roles in measuring true performance of the public projects. It was also revealed that the design complexity, financial structure and government policy are the three main factors affecting risks across time, cost and operational performance in PPP projects. These findings show that some of the usual construction related risks easily propagate through the project network in a PPP project and impact on long-term operation over the post-construction phase. Thus, the findings assert that the long term engagement of the private agencies in complex PPP projects not only imposes time and cost related risks over project development phases but also triggers performance related risks in project operational context.

\section{RELIABILITY OF THE FACTOR ATTRIBUTES IN THE DATASET}

Reliability analysis examines the internal consistency of the perceived attributes among the respondents from the average correlation among the attributes and the number of total attributes in the sample (Doloi, 2008). Cronbach's alpha test was performed to compute the internal consistency for the attributes under each factor and overall attributes. Cronbach's alpha Ca can vary from 0 to 1 , where the value close to 1 indicates high consistency in the dataset.

The value of $\mathrm{Ca}$ is dependent on the number of variables, therefore there is no fixed 
boundary for $\mathrm{Ca}$ to be acceptable (Zhang, 2005a). However, George and Mallery (2000) suggested typical values of $\mathrm{C}_{\alpha}$ which applied in most cases: $\mathrm{C}_{\alpha}>0.9$ denotes excellent, 0.9 $>\mathrm{C}_{\alpha}>0.8$ as good, $0.8>\mathrm{C}_{\alpha}>0.7$ as acceptable, $0.7>\mathrm{C}_{\alpha}>0.6$ as questionable, $0.6>\mathrm{C}_{\alpha}>0.5$ as poor, and $0.5>\mathrm{C}_{\alpha}$ denotes unacceptable.

Table 5 shows the values of the Cronbach's alpha $\left(\mathrm{C}_{\alpha}\right)$ for the attributes under each factor. As all $\mathrm{C}_{\alpha}$ values are in the range of $(0.8,1.0)$, the measured attributes are considered to be highly consistent and reliable.

\section{REGRESSION MODELLING OF COST, TIME AND OPERATIONAL PERFORMANCE}

In the previous section, factor analysis was used to identify the major attributes count for the time, cost and operational performance. However, how these attributes are related to the overall success remains obscure in factor analysis (Doloi, 2009). In this section, multiple linear regression technique was applied to investigate the relationship between major risk attributes and the success in terms of time, cost and operational performance.

In regression model, the dependent variables are considered as linear combination of the independent or explanatory variables. The independent variables are the attributes which are considered to contribute to the time, cost and/or operational performance, and the de- pendent variable associated with the project success are time $\left(Y_{1}\right)$, cost $\left(Y_{2}\right)$ and operational performance $\left(Y_{3}\right)$. In this research, the reduced risk attributes under the seven factors as listed in Table 4 were entered into the regression model stepwise as categorical variables, therefore the impacts of the attributes can be quantified according to the following equation (Field, 2005):

$$
Y i=\beta_{0}+\beta_{1} x_{1 i}+\beta_{2} x_{2 i}+\beta_{3} x_{3 i}+\ldots+\beta_{j} x_{j i}+\varepsilon_{i}
$$

where: $Y=$ value of dependent valuables (one of three success criteria of time, cost and quality); $\beta_{0}=$ constant and the intercept at the $Y$ axis; $\beta_{1}$ to $\beta_{j}=$ estimated regression coefficients; $x_{1}$ to $x_{j}=$ values of the independent or predictor variables; $\varepsilon_{i}=$ error term, which is a random variable with mean 0 ; and $i=$ index of the performance variable being predicted.

According to the result from factor analysis, the variation of time, cost and operational performance can be explained by and large from the major factors in Tables 2, 3 and 4. Due to the small sample size, the number of explanatory variables has to be diminished to minimize the impact of weak predictive models (Doloi, 2009). Spearman's correlation analysis was performed in the first place, to screen out the factors with insignificant correlation $(p>0.05)$ to the three success criteria: time, cost and operational performance (Ling et al., 2004). Then the correlated variables were entered stepwise

Table 5. Reliability analysis

\begin{tabular}{llll}
\hline Attributes & Cronbach's alpha $(\mathrm{Ca})$ & \\
\cline { 2 - 4 } & $\begin{array}{l}\text { Time performance } \\
\text { (Ref. Table 2) }\end{array}$ & $\begin{array}{l}\text { Cost performance } \\
\text { (Ref. Table 3) }\end{array}$ & $\begin{array}{l}\text { Operational performance } \\
\text { (Ref. Table 4) }\end{array}$ \\
\hline Attributes in Factor 1 & 0.903 & 0.911 & 0.931 \\
Attributes in Factor 2 & 0.836 & 0.920 & 0.897 \\
Attributes in Factor 3 & 0.949 & 0.899 & 0.913 \\
Attributes in Factor 4 & 0.941 & 0.930 & 0.983 \\
Attributes in Factor 5 & 0.898 & 0.865 & 0.869 \\
Attributes in Factor 6 & 0.876 & 0.857 & 0.975 \\
Attributes in Factor 7 & & 0.828 & 0.911 \\
All attributes & 0.981 & 0.899 & 0.902 \\
\hline
\end{tabular}


as categorical independent variables against the success criteria. As mentioned earlier, the data for success criteria in terms of time, cost and operational performance were independently collected from the respondents in the questionnaire survey (refer to Appendix A). The goodness of fit for the model was measured by the coefficient of determination $R^{2}$ and the adjusted coefficient of determination $\bar{R}^{2}$, which were used to select the optimal models. The value of $R^{2}$ will change rapidly with the addition of new attributes into the model, whereas $\bar{R}^{2}$ takes the generalisation capability of the model into consideration. Criterion $R^{2}$ and $\bar{R}^{2}$ should be very close to accept the model (Field, 2005). According to the result of regression shown in Table 6 , all the three derived models are acceptable.

The final regression model for cost performance is shown as follows:
Cost Performance $=2.654+$

0.507 (partner's dispute) +

0.466 (misunderstanding of contracts) +

0.402 (Changes in output specifications) +

0.392 (Adverse change in interest rate)

In the result, misunderstanding of contract $(\beta=0.466)$ and Partner's dispute $(\beta=0.507)$ shows significant impact on the cost performance, which is consistent with the result of factor analysis and previous studies. (Frimpong et al., 2003; Sambasivan and Soon, 2007) Adverse change in interest rate $(\beta=0.4392)$ reflect the factor of inflation, which affects the material and labor cost, and subsequently cause cost overrun (Arditi et al., 1985; Kaming et al., 1997). In addition, change in output specification also exhibits strong relationship with cost performance, which is consistent with the result from Nassar et al. (2005). These findings

Table 6. Results of multiple regression analysis

\begin{tabular}{|c|c|c|c|c|c|}
\hline Variable & B Coefficient & $\mathrm{SE}$ & $\mathrm{t}$-value & Sig. (p) & $\mathrm{R}^{2} /$ Adjusted $\mathrm{R}^{2}$ \\
\hline \multicolumn{6}{|l|}{ Cost performance } \\
\hline Constant & 2.654 & 0.248 & 2.320 & 0.001 & $0.3678 / 0.3543$ \\
\hline 29. Partner's dispute & 0.507 & 0.031 & 2.562 & 0.023 & $\mathrm{~F}=7.893$ \\
\hline $\begin{array}{l}\text { 30. Misinterpretation of } \\
\text { contracts }\end{array}$ & 0.466 & 0.098 & 1.764 & 0.054 & $\mathrm{p}=0.0001$ \\
\hline $\begin{array}{l}\text { 1. Changes in output } \\
\text { specifications }\end{array}$ & 0.402 & 0.020 & 1.146 & 0.023 & Dublin-Watson $=1.980$ \\
\hline $\begin{array}{l}\text { 36. Adverse change in } \\
\text { interest rate }\end{array}$ & 0.392 & 0.012 & 1.926 & 0.017 & \\
\hline \multicolumn{6}{|l|}{ Time performance } \\
\hline Constant & 2.453 & 0.234 & 2.457 & 0.001 & $0.3854 / 0.3871$ \\
\hline 6. Constructability & 0.551 & 0.018 & 1.939 & 0.023 & $\mathrm{~F}=8.023$ \\
\hline 29. Partner's dispute & 0.503 & 0.021 & 2.198 & 0.024 & $p=0.0001$ \\
\hline 3. Design complexity & 0.487 & 0.012 & 2.310 & 0.019 & Dublin- Watson $=1.909$ \\
\hline $\begin{array}{l}\text { 30. Misinterpretation of } \\
\text { contracts }\end{array}$ & 0.406 & 0.110 & 2.122 & 0.023 & \\
\hline \multicolumn{6}{|l|}{ Operational performance } \\
\hline Constant & 2.984 & 0.288 & 2.877 & 0.001 & $0.35670 / 0.3534$ \\
\hline 19. Technical obsolescence & 0.553 & 0.012 & 2.982 & 0.024 & $\mathrm{~F}=8.034$ \\
\hline 10. Defects in construction & 0.497 & 0.013 & 2.123 & 0.031 & $p=0.0001$ \\
\hline 28. Increased competition & 0.476 & 0.016 & 1.872 & 0.054 & Dublin - Watson $=1.932$ \\
\hline $\begin{array}{l}\text { 15. Demand below } \\
\text { anticipations }\end{array}$ & 0.392 & 0.101 & 1.902 & 0.025 & \\
\hline
\end{tabular}

Note: Variables are significant at $\mathrm{p}<0.05$. 
suggest that clear definition of scope of work in the beginning of the project plays a significant role in improving cost performance, as it can largely reduce the likelihood of changing the output specification, misunderstanding of contracts, as well as partner's dispute.

The final regression model for time performance is shown as follows:

Time Performance $=2.453+$
0.551 (constructability) +
0.503 (partner's dispute) +
0.487 (Design complexity) +
0.406 (misinterpretation of contracts)

Misunderstanding of contract $(\beta=0.406)$ and partner's dispute $(\beta=0.503)$ are deemed as major factors that affects the time performance of the project, which is consistent with the result from factor analysis. As partner's dispute is strongly correlated with misunderstanding of contracts in nature, it is not surprisingly that both factors have a high impact on the time performance (Frimpong et al., 2003). Other factors that affect the time performance greatly are the complexity of the project, including constructability $(\beta=0.551)$ and design complexity $(\beta=0.487)$. The complexity of the project may increase the likelihood of changes and mistakes in design and construction phase, which subsequently affects the time performance (Kaming et al., 1997; Sambasivan and Soon, 2007).

Finally, the operational performance is shown as follows:

\section{Operational Performance $=2.984+$ 0.553 (technical obsolescence) + 0.497 (Defects in construction) + 0.476 (increased competition) + 0.392 (Demand below anticipations)}

According to Miller and Lessard (2001), the risks in engineering projects can be categorized into market-related, completion (technical) and institutional risks. From the result, operational performance is largely affected by the market-related risks, including the increase of competition $(\beta=0.476)$, unexpected low demand ( $\beta=0.392)$. This finding is consistent with the research of PPP risks in UK (Bing et al., 2005). Technical-related risks also play an important role on operational performance, such as technical obsolescence $(\beta=0.553)$ and construction defect $(\beta=0.497)$. The fact that operational performance largely depends on market-related factors and technical obsolescence is due to the long term nature of operational phase. As the major cost component shift from material/labor cost to maintenance and overhead cost in operational cost, interest rate and inflation does not have much impact on the performance. Design defect is another important factor that affects the operational cost as well, as suggested by quality management principles (Antony and Banuelas Coronado, 2002; Arditi and Gunaydin, 1997).

\section{CONCLUSION}

This study aimed to achieve an added understanding on risk spectrum associated with the features of PPP projects. The focus of this research was predominately on the quantification of risks associated with cost, time and operational performance in PPP projects and to developing an understanding on the crossovers in the complex project network. This in effect assists a clearer understanding of the distinction between traditionally procured projects and PPP projects. One of the key contributions of this research is that the elements of the PPP projects are highly interrelated and construction related risks easily propagate through the project network. PPP projects are often complex and the long term engagement of the private agencies in PPP projects not only exposes time and cost related risks over project development phases but also triggers performance related risks in project operational context. 
Project cost, time and operational performance are important evaluation criteria for project management and the variables affecting it are crucial for project success regardless of the procurement strategy adopted. The identification of critical factors and quantification of the risk variables that affect project cost, time and operational performance will acquaint construction practitioners who have no prior background in PPP procurement to the specifics of PPP and distinct it from traditionally procured projects (Daube et al., 2008). The success in modeling an efficient PPP framework relies on the integration of the underlying risk and efficient management over entire project life.

It was found that the design complexity, financial structure and government policy influences are the three main factors affecting risks across time, cost and operational performance in PPP projects. This further accentuates the criticality of the finance and tendering phase of the PPP project life cycle. The criticality of the different risk factors and variables across project cost, time and operational project performance are fairly analogous. Suffice to say, if a particular risk has a high degree of influence in cost and time performance in the construction phase, there is a potential chance that the same risk will affect the operational performance in the post construction phase as well. However, the criticality of the risks affecting cost is generally higher than that of time and operational performance. So if the risks could be mitigated to control the project cost, the benefit will be reflected across project time control and operational project performance.

Limitations of the research: Though best efforts were put in this research and findings do make a significant contribution for industry, this research is not free from limitations. Firstly, the sample size of 114 from seven PPP projects is the Australian state of Victoria may not be considered true representation of the diverse nature of PPP projects and risks as- sociated to the locational scope. Secondly, the respondents are not evenly distributed among the professional roles which may have induced some bias in responses. Thus the predictive models formed may be further honed based on detailed discussions and suggestions of industry experts from other states across the country. Moreover, the highlights of the impacts of key risk attributes on cost, time and operation performance should be further tested in global contexts. The relationship between various risk sources and its impact on performance across three dimensions namely cost, time and operations over the lifecycle has to be detailed further which is author's intended future work.

\section{REFERENCES}

Akintoye, A. S. and MacLeod, M. J. (1997) Risk analysis and management in construction, International Journal of Project Management, 15(1), pp. 31-38. http://dx.doi.org/10.1016/ S0263-7863(96)00035-X

Antony, J. and Coronado, R. Banuelas (2002) Design for six sigma, Manufacturing Engineer, 81(1), pp. 24-26. http://dx.doi.org/10.1049/me:20020102

Arditi, D., Akan, G. T. and Gurdamar, S. (1985) Cost overruns in public projects, International Journal of Project Management, 3(4), pp. 218224.

http://dx.doi.org/10.1016/0263-7863(85)90053-5

Arditi, D. and Gunaydin, H. M. (1997) Total quality management in the construction process, International Journal of Project Management, 15(4), pp. 235-243. http://dx.doi.org/10.1016/ S0263-7863(96)00076-2

Baker, S., Ponniah, D. and Smith, S. (1999) Risk response techniques employed currently for major projects, Construction Management and Economics, 17(2), pp. 205-213. http://dx.doi.org/10.1080/014461999

Baloi, D. and Price, A. D. F. (2003) Modelling global risk factors affecting construction cost performance, International Journal of Project Management, 21(4), pp. 261-269. http://dx.doi. org/10.1016/S0263-7863(02)00017-0 
Bing, L., Akintoye, A., Edwards, P. J. and Hardcastle, C. (2005) The allocation of risk in PPP/ PFI construction projects in the UK, International Journal of Project Management, 23(1), pp. 25-35. http://dx.doi.org/10.1016/j.ijproman.2004.04.006

Chan, D. W. M. and Kumaraswamy, M. M. (1997) A comparative study of causes of time overruns in Hong Kong construction projects, International Journal of Project Management, 15(1), pp. 55-63. http://dx.doi.org/10.1016/S02637863(96)00039-7

Cheung, E., Chan, A. P. C. and Kajewski, S. (2010) The public sector's perspective on procuring public works projects - comparing the views of practitioners in Hong Kong and Australia, Journal of Civil Engineering and Management, 16(1), pp. 19-32.

http://dx.doi.org/10.3846/jcem.2010.02

Child, D. (1990) The essentials of factor analysis. Cassell Educational Ltd.

Cooper, D. and Chapman, C. (1987) Risk analysis for large projects: models, methods and cases. John Wiley and Sons.

Daube, D., Vollrath, S. and Alfen, H. W. (2008) A comparison of project finance and the forfeiting model as financing forms for PPP projects in Germany, International Journal of Project Management, 26(4), pp. 376-387. http://dx.doi.org/10.1016/j.ijproman.2007.07.001

Dikmen, I., Birgonul, M. T. and Han, S. (2007) Using fuzzy risk assessment to rate cost overrun risk in international construction projects, International Journal of Project Management, 25(5), pp. 494-505.

http://dx.doi.org/10.1016/j.ijproman.2006.12.002

Doloi, H. (2008) Analysing the novated design and construct contract from the client's, design team's and contractor's perspectives, Constuction Management and Economics, 26(11), pp. 1181-1196.

http://dx.doi.org/10.1080/01446190802512359

Doloi, H. (2009) Analysis of pre-qualification criteria in contractor selection and their impacts on project success, Construction Management and Economics, 27(12), pp. 1245-1263.

http://dx.doi.org/10.1080/01446190903394541

Doloi, H. and Raisbeck, P. (2007) Quantification and modelling of retained risk in Public-Private Partnership (PPP) projects. In: 4th International Structural Engineering and Construc- tion Conference, 26th-28th September 2007, Grand Hyatt, Melbourne, Australia.

Doloi, H. K. (2010) Understanding stakeholders' perspective of cost estimation in project management, International Journal of Project Management, 29(5), pp. 622-636.

http://dx.doi.org/10.1016/j.ijproman.2010.06.001

Field, A. (2005) Discovering statistics using SPSS. London: SAGE Publications.

Fornell, C. and Larcker, D. F. (1981) Evaluating structural equation models with unobservable variables and measurement error, Journal of Marketing Research, 18(1), pp. 39-50. http://dx.doi.org/10.2307/3151312

Frimpong, Y., Oluwoye, J. and Crawford, L. (2003) Causes of delay and cost overruns in construction of groundwater projects in a developing countries; Ghana as a case study, International Journal of Project Management, 21(5), pp. 321-326. http://dx.doi.org/10.1016/S02637863(02)00055-8

George, D. and Mallery, P. (2000) SPSS for Windows step by step: a simple guide and reference 9.0 update. Boston, Allyn and Bacon.

Ghosh, S. and Jintanapakanont, J. (2004) Identifying and assessing the critical risk factors in an underground rail project in Thailand: a factor analysis approach, International Journal of Project Management, 22(8), pp. 633-643. http://dx.doi.org/10.1016/j.ijproman.2004.05.004

Groak, S. (1994) Is construction an industry? Notes towards a greater analytical emphasis on external linkages, Construction Management and Economics, 12(4), pp. 287-293. http://dx.doi.org/10.1080/01446199400000038

Iyer, K. C. and Jha, K. N. (2005) Factors affective cost performance: evidence from the Indian construction projects, International Journal of Project Management, 23(4), pp. 283-295. http:// dx.doi.org/10.1016/j.ijproman.2004.10.003

Jin, X. and Doloi, H. (2009) Modelling risk allocation in privately financed infrastructure projects using fuzzy logic, Computer-Aided Civil and Infrastructure Engineering, 24(7), pp. 509-524. http://dx.doi.org/10.1111/j.14678667.2009.00609.x

Kaming, P. F., Olomolaiye, P. O., Holt, G. D. and Harris, F. C. (1997) Factors influencing construction time and cost overruns on high-rise projects in Indonesia, Construction Manage- 
ment and Economics, 15(1), pp. 83-94.

http://dx.doi.org/10.1080/014461997373132

Kumaraswamy, M. M. and Matthews, J. D. (2000) Improved subcontractor selection employing partnering principles, Journal of Management in Engineering-ASCE, 16(3), pp. 47-57. http://dx.doi.org/10.1061/(ASCE)0742597X(2000)16:3(47)

Kuronen, M., Luoma-Halkola, J., Junnila, S., Heywood, C. and Majamaa, W. (2011) Viable urban redevelopments - exchanging equity for energy efficiency, International Journal of Strategic Property Management, 15(3), pp. 205-221. http://dx.doi.org/10.3846/164871 5X.2011.613230

Lam, J. T. M. (2004) Public private partnerships in the Hong Kong public sector: a right approach?, Journal of Academy of Business and Economics, 3(1), pp. 198-202.

Ling, F. Y. Y., Chan, S. L., Chong, E. and Ee, L. P. (2004) Predicting performance of design-build and design-bid-build projects, Journal of Construction Engineering and Management-ASCE, 130(1), pp. 75-83. http://dx.doi.org/10.1061/ (ASCE)0733-9364(2004)130:1(75)

Lyons, T. and Skitmore, M. (2004) Project risk management in the Queensland engineering construction industry: a survey, International Journal of Project Management, 22(1), pp. 51-61. http://dx.doi.org/10.1016/S02637863(03)00005-X

Majamaa, W., Junnila, S., Doloi, H. and Niemistö, E. (2008) End-user oriented public-private partnerships in real estate industry, International Journal of Strategic Property Management, 12(1), pp. 1-17. http://dx.doi.org/10.3846/1648715X.2008.12.1-17

Marle, F., Vidal, L.-A. and Bocquet, J.-C. (2010) Interactions-based risk clustering methodologies and algorithms for complex project management, International Journal of Production Economics http://dx.doi.org/10.1016/j.ijpe.2010.11.022

Miller, R. and Lessard, D. (2001) Understanding and managing risks in large engineering projects, International Journal of Project Management, 19(8), pp. 437-443. http://dx.doi. org/10.1016/S0263-7863(01)00045-X

Nassar, K. M., Nassar, W. M. and Hegab, M. Y. (2005) Evaluating cost overruns of asphalt paving project using statistical process control methods, Journal of Construction Engineering and Management-ASCE, 131(11), pp. 11731178. http://dx.doi.org/10.1061/(ASCE)07339364(2005)131:11(1173)

Nunnally, J. C. (1978) Psychometric theory. New York: McGraw-Hill.

Partnerships UK (2006) Report on operational PFI projects. Partnerships UK.

PMBOK (2008) A guide to project management body of knowledge (PMBOK guide). Project Management Institute.

Poulter, T. (2004) Building Australia with PPP. Sydney.

Sambasivan, M. and Soon, Y. W. (2007) Causes and effects of delays in Malaysian construction industry, International Journal of Project Management, 25(5), pp. 517-526.

http://dx.doi.org/10.1016/j.ijproman.2006.11.007

SDTF (2006) The Secretary Department of treasury and finance - Partnerships Victoria, Guidance material - July 2006, Overview, Department of treasury and finance, Melbourne.

Smith, N. J. and Merna, T. (2006) Managing risk in construction project. Blackwell Publishing.

Tang, W., Qiang, M., Duffield, C. F., Young, D. M. and Lu, Y. (2007) Risk management in the Chinese construction industry, Journal of Construction Engineering and Management, 133(12), pp. 944-956. http://dx.doi.org/10.1061/ (ASCE)0733-9364(2007)133:12(944)

Trost, S. M. and Oberlender, G. D. (2003) Predicting accuracy of early cost estimates using factor analysis and multivariate regression, Journal of Construction Engineering and Management-ASCE, 129(2), pp. 198-204. http://dx.doi. org/10.1061/(ASCE)0733-9364(2003)129:2(198)

Vaus, D. A. (2001) Research design in social science. London: Sage Publications Ltd.

Wooward, J. (1997) Construction project management: getting it right the first time. London: Thomas Telford.

Xenidis, Y. and Angelides, D. (2005) The financial risks in build-operate-transfer projects, Construction Management and Economics, 23(4), pp. 431-441. http://dx.doi.org/10.1080/01446190500041552

Xu, Y., Yang, Y., Chan, A. P. C., Yeung, J. F. Y. and Cheng, H. (2011) Identification and allocation of risks associated with PPP water projects in China, International Journal of Strategic Prop- 
erty Management, 15(3), pp. 275-294.

http://dx.doi.org/10.3846/1648715X.2011.617867

Yuan, J. F., Skibniewski, M. J., Li, Q. and Shan, J. (2010) The driving factors of China's publicprivate partnership projects in Metropolitian transportation systems: public sector's viewpoint, Journal of Civil Engineering and Management, 16(1), pp. 5-18.

http://dx.doi.org/10.3846/jcem.2010.01

Zhang, X. (2005a) Concessionaire's financial capabiliy in developing build-operate-transfer type infrastructure projects, Journal of Construction Engineering and Management-ASCE, 131(10), pp. 1054-1064. http://dx.doi.org/10.1061/ (ASCE)0733-9364(2005)131:10(1054)

Zhang, X. (2005b) Financial viability analysis and capital structure optimization in privatized public infrastructure projects, Journal of Construction Engineering and Management, 131(6), pp. 656-668. http://dx.doi.org/10.1061/ (ASCE)0733-9364(2005)131:6(656)

Zou, P. X. W., Zhang, G. and Wang, J. (2007) Understanding the key risks in construction projects in China, International Journal of Project Management, 25(6), pp. 601-614. http://dx.doi. org/10.1016/j.ijproman.2007.03.001

APPENDIX A. Excerpt of the survey questionnaire

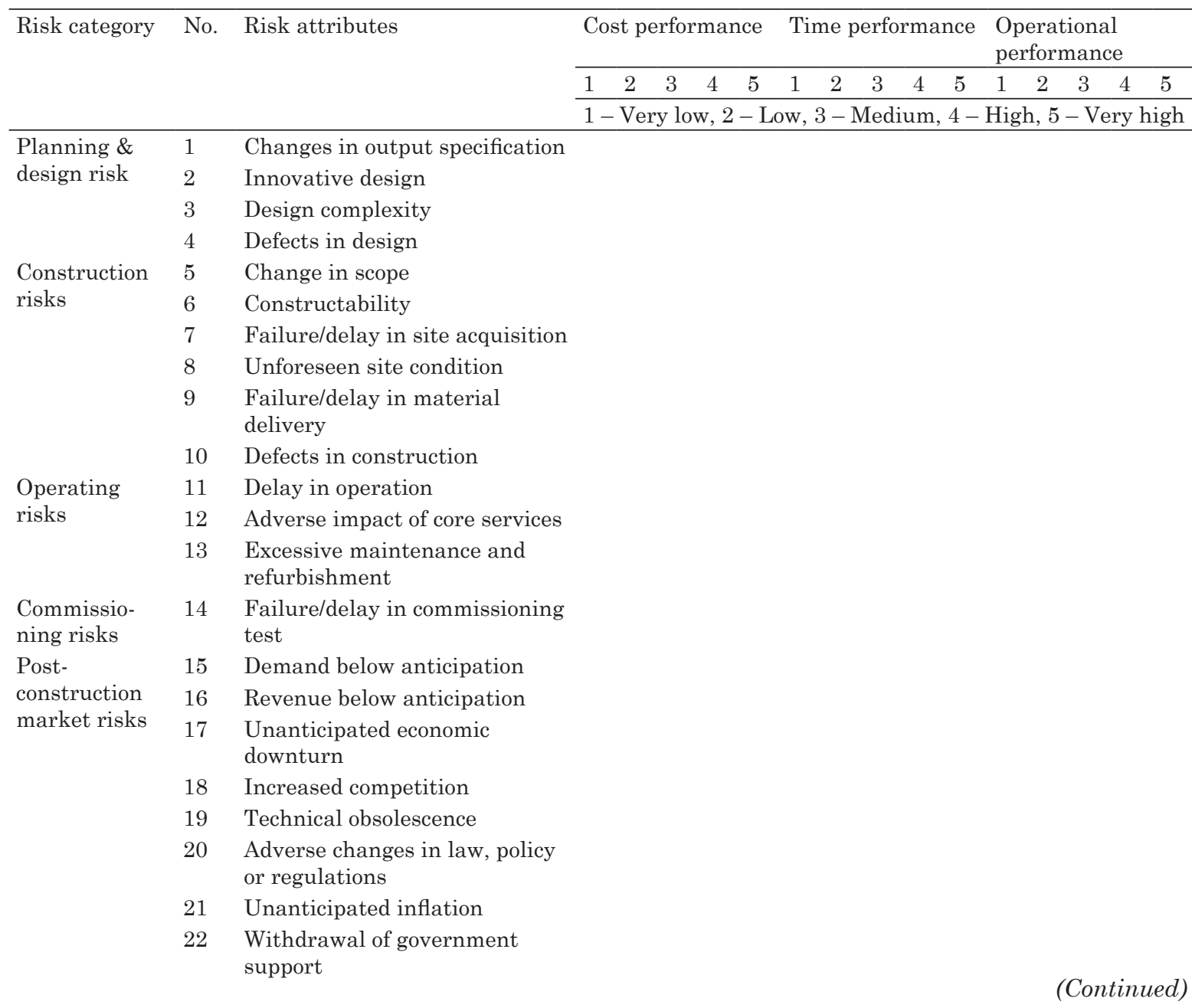




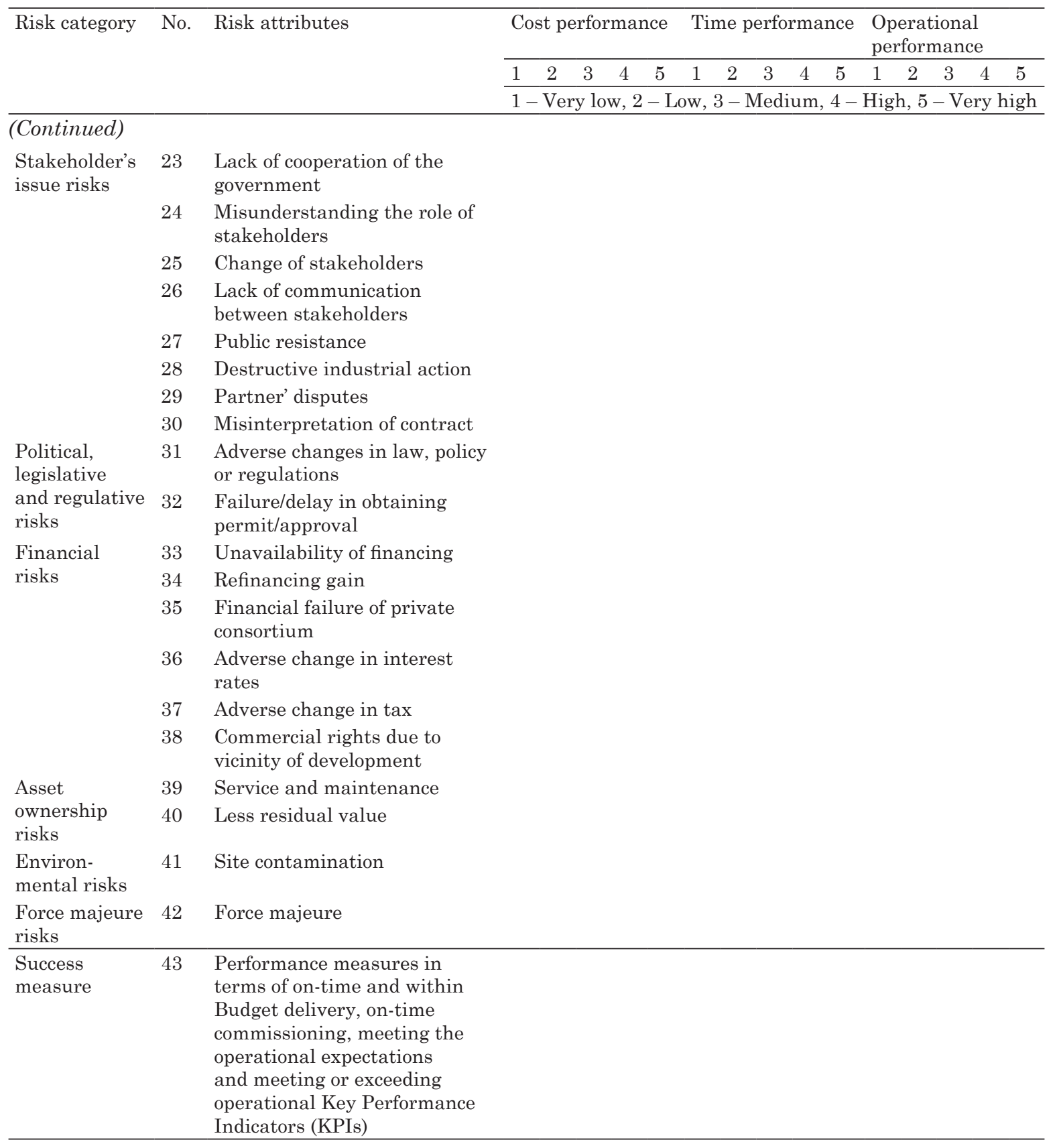

